\title{
International Journal of Cardiovascular Imaging Effect of atrial fibrillation ablation on myocardial function: insights from cardiac magnetic resonance feature tracking analysis --Manuscript Draft--
}

\begin{tabular}{|c|c|}
\hline Manuscript Number: & CAIM-D-13-00266R1 \\
\hline Keywords: & $\begin{array}{l}\text { Feature tracking; atrial fibrillation; Ablation; Cardiovascular magnetic resonance; } \\
\text { Wall motion }\end{array}$ \\
\hline \multicolumn{2}{|l|}{$\begin{array}{l}\text { Corresponding Author Secondary } \\
\text { Information: }\end{array}$} \\
\hline \multicolumn{2}{|l|}{$\begin{array}{l}\text { Corresponding Author's Secondary } \\
\text { Institution: }\end{array}$} \\
\hline First Author: & Felix Ceelen \\
\hline \multicolumn{2}{|l|}{ First Author Secondary Information: } \\
\hline \multirow[t]{5}{*}{ Order of Authors: } & Felix Ceelen \\
\hline & Ross J Hunter, M.D. \\
\hline & Redha Boubertakh \\
\hline & Wieland H Sommer, M.D. \\
\hline & Marco Armbruster \\
\hline
\end{tabular}


AF patients undergoing ablation appear to have near normal cardiac wall motion, which does not improve following successful ablation. Feature tracking analysis is a reliable tool to determine treatment effects but is more likely to show positive findings if the population is unhealthy.

\section{Response to Reviewers:}

Reviewer \#1: We would like to thank this reviewer for the thoughtful comments and suggestions. We address these below and have revised our manuscript accordingly. We feel this process has significantly improved the revised manuscript.

The observer variability of longitudinal strain seems to be very high, which tracking algorithm software release did you exactly use?

After consulting TomTec Imaging Systems $\mathrm{GmbH}$ we could ascertain that tracking algorithm software 2D CPA-MR Ver. 1.1.2.36 - b. 120712 was used during our analysis. The intra-observer variability in the 4-chamber view is possibly affected by the breath-dependent position of the diaphragm [see reference 7 in the manuscript]. Our variability for most parameters is comparable to previously published data. However, we are grateful that this reviewer noted that our longitudinal strain variability was higher than in two previously reported studies (our data 25.6\%, 12.3\% for Augustine et al (JCMR 2013, see reference 7 in the manuscript), 17.3\% for Schuster et al (EJR 2013, see reference 23 in the manuscript). As both other studies do not report the tracking algorithm version details it is difficult to speculate on the reasons for this difference in longitudinal strain variability.

How did you calculate mean longitudinal and circumferential strain? We apologize for the lack of clarity in the manuscript. In order to clarify this detail in our methods section, we added the following sentence to the revised manuscript: "Consequently, a curve of mean tracking values over the cardiac cycle was generated."

Where do you exactly see the clinical field of application of this approach? Please highlight this in your results and discussion.

We agree that it is important to outline the potential clinical utility of this technology and have added text to the manuscript as follows:

"The use of semi-automated feature tracking software for detailed analysis of systolic and diastolic function has now been validated in several studies. This paves the way for clinical studies examining its utility in a number of potential areas, such as quantifying mechanical dyssynchrony and patient selection for CRT, assessment of ischaemia and viability, early detection of cardiomyopathies such as hypertrophic cardiomyopathy or arrhythmogenic cardiomyopathy and possibly detection of genotype positive but apparently phenotype negative patients."

What is the benefit for the patient when using this technique before and after ablation. Again we agree this should be explained and have added text following on from the paragraph above as follows.

"The application of this technology to AF is particularly exciting because its aetiology is likely multifactorial and may well involve abnormalities of cardiac function and haemodynamics in a proportion of patients which causes atrial remodelling and thereby promotes AF [24,25]. The onset of AF may also precipitate heart failure in some patients and increases mortality in those with pre-existing heart failure [26,27]. A greater understanding of what abnormalities promote AF, how AF adversely affects the heart, and who will respond best to restoration of sinus rhythm will better equip us to prevent AF with upstream therapies and help select patients for curative strategies."

Can you identify responder?

This would be an interesting question to answer and an answer in itself to your previous question about the potential clinical use of feature tracking in ablation candidates. However, our data do not allow this prediction of responders, as the baseline values are too normal. We think, that future studies should try to seek this out by recruiting a patient group with reduced cardiac function.

Feature tracking provides a lot of parameters. Which are the relevant ones? Please focus in your paper.

Again, we fully agree that it would be very helpful to decrease the amount of parameters that have to be observed. We analysed all the parameters to be able to demonstrate which components would change (e.g. systolic vs diastolic, longitudinal vs radial etc). As there is no prior data on which strain component may be altered first, we 
could not pre-specify one or two parameters. We are aware of the potential for multiplicity issues leading to false rejection of null hypotheses tested. This is why we did not claim clinical significance for single statistically different values.

Reviewer \#2: We would like to thank this reviewer for the thoughtful comments and suggestions. We address these below and have revised our manuscript accordingly. We feel this process has significantly improved the revised manuscript.

Please re-arrange the descriptive part and probably use abbreviations to make it less confusing

We thank the reviewer for this comment. We replaced several words by using their aforementioned abbreviations. As far as the feature tracking terms are concerned, we followed the often-advised avoidance of abbreviations since the reader is not yet familiar with these special terms. If the reviewer, editor and publishers feel otherwise, we would be happy to create abbreviations.

A pre-post table only of the parameters that changed with their individual $p$ values might be more descriptive than the overall figure 2 .

We thank the reviewer for this valuable comment. We have changed this as suggested. Please see Table 2 in the revised table document. 


\section{Introduction}

Atrial fibrillation (AF) is the most common heart arrhythmia. It is associated with a reduction in quality of life, an increase in disease-related hospitalizations, complications such as stroke and heart failure as well as increased mortality [1]. Hence, treatment of AF is important to lower the rate of these complications.

By isolating the initiating foci of $\mathrm{AF}$, catheter ablation has emerged as an effective and potentially curative treatment option in patients with paroxysmal and persistent AF. Furthermore, reverse atrial remodelling and functional improvement of the left atrium (LA) has been reported after successful ablation procedures [2,3]. Similarly, restoration of sinus rhythm may result in an improvement of left ventricular (LV) function, especially diastolic function [4-6].

Cardiovascular magnetic resonance (CMR) is considered the gold standard in assessing global and regional cardiac function due to its high accuracy and excellent reproducibility [4]. CMR feature tracking, which is a novel post-processing technique similar to echocardiographic speckle tracking, which tracks regional myocardial features throughout the cardiac cycle. With this technique, myocardial strain and velocity measurements can be derived directly from cine images [7].

Earlier studies have shown that LV ejection fraction (EF) improves in successfully ablated patients with systolic heart failure [8-10]. However, ejection fraction is a fairly crude parameter of systolic function, and a preserved ejection fraction does not exclude subtle abnormalities of both systolic and diastolic function. Morton et al. summarize that impaired myocardial strain can occur without any detectable changes in LV volumes or function. They furthermore conclude that strain imaging may allow early or subtle detection of abnormalities [4]. 
Consequently this study aimed to analyse existence and reversibility of subclinical cardiac dysfunction following atrial fibrillation ablation using CMR feature tracking.

\section{Methods}

\section{Study population}

This is a prospective single centre study. Consecutive consenting patients with paroxysmal AF refractory to medical management were recruited for catheter ablation. Patients were randomly allocated to undergo pulmonary vein isolation by wide are circumferential ablation (WACA) using radiofrequency energy or ostial cryo-ablation with the cryo-balloon (Cryo). CMR was performed pre-ablation and repeated at 3 months post ablation.

Patients were excluded from recruitment if they showed persistent atrial fibrillation since persistent atrial fibrillation diminishes the quality of MR imaging.

Informed consent to the CMR examinations was obtained from all study patients. The study was approved by a local research ethics committee (UK) and performed in accordance with local data protection laws and regulations.

\section{Control subjects}

In order to investigate the health status of our cohort of AF patients with regard to feature tracking parameters, a meta-analysis was performed to compare published healthy volunteers' tracking data to our data at baseline. We searched PubMed throughout January 2013 using the search term "feature tracking cardiac MRI". Studies were considered as suitable, if they reported strain values in a healthy cohort. In addition, expert opinions (S.E.P., W.H.S.) were 
obtained, whether any potentially relevant study was missed. Consequently, the data of these manuscripts were analysed in order to get representative comparison data for a healthy reference collective.

\section{Catheter ablation procedure}

The catheter ablation procedure was aimed at electrical isolation of all pulmonary veins (PV) from the LA and has been described in more detail elsewhere [11]. In brief, pulmonary vein isolation (PVI) was achieved by applying either radiofrequency energy (WACA) or freezing (Cryo). For WACA a $3.5 \mathrm{~mm}$ irrigated ablation catheter (Thermo-Cool Celsius ${ }^{\circledR}$ or Navistar ${ }^{\circledR}$, Biosense Webster, CA, USA) was used to place contiguous lesions in the left atrium $1-2 \mathrm{~cm}$ from the pulmonary vein ostia to isolate them as ipsilateral pairs. For Cryo, a cryo-balloon (Arctic Front $^{\circledR}$, Medtronic, CA, USA) was inflated in the left atrium and advanced into the pulmonary vein ostia to isolate each vein at its ostium.

PVI was then confirmed by a PV mapping catheter as described previously [12].

\section{Follow-up}

To determine therapeutic success, patients were asked to undergo a cardiac assessment three and six months post ablation procedure. After seven days of ambulatory ECG monitoring at these visits, intervention success was defined as absence of AF or any other atrial tachyarrhythmia lasting $\geq 30$ seconds without taking anti-arrhythmic drugs subsequent to a three month blanking period, following current guidelines [13]. 


\section{Cardiovascular Magnetic Resonance (CMR) protocol}

MR imaging was performed on a 1.5T MR-scanner (Achieva ${ }^{\circledR}$, Philips Healthcare, Eindhoven, The Netherlands) using a 32-channel surface coil (Invivo ${ }^{\circledR}$, Orlando, FL, US). Balanced Steady-State Free Precession (SSFP) cine images were acquired in the 2-chamber, 4-chamber and the short-axis orientations to perform LV function analysis. Typical scan parameters were: $\mathrm{TR} / \mathrm{TE}=3.2 / 1.6 \mathrm{~ms}$, SENSE parallel imaging acceleration factor $=1.5$ to 2 , slice thickness $=8 \mathrm{~mm}$, slice gap $=2 \mathrm{~mm}, 1.9 \times 2 \mathrm{~mm}^{2}$ acquired spatial resolution and 30 cardiac phases with $67 \%$ phase sharing. In addition, left atrial cines covering all of the atria (12 slices) were acquired in the same orientation as the short-axis stack using a $5 \mathrm{~mm}$ slice thickness and no slice gap.

\section{Image Analysis}

All images were anonymized and then analyzed by two independent observers (F.C., 4 months standardised training of CMR image analysis and S.E.P., 14 years of CMR experience).

\section{Volumetry}

All measurements were assessed using certified software $\left(\mathrm{cvi}^{42}{ }^{2}\right.$, Circle Cardiovascular Imaging Inc., Calgary, CA). Endocardial and epicardial contours were drawn manually for volumetry of the LV at end-systole and end-diastole on all short-axis slices. To define the most basal image, both observers took into account a content of circumferential myocardium of at least $50 \%$ and a visual control of the short-axis slice position on the 4-chamber view as described previously $[14,15,5]$. Papillary muscles and trabeculations were excluded from LV mass and included in volume calculations. To measure left atrial volumes, contours were drawn with the multiple slice method using the same end-diastolic and end-systolic cardiac phases as determined from LV volumes [16]. Pulmonary veins were excluded at their ostia and the left atrial appendage was excluded at its base. LA volume was automatically 
calculated from all the included slices. Subsequently, LV and LA function was determined by calculating the ejection fraction with the following formula: ejection fraction $=100 *(\mathrm{EDV}-$ ESV)/EDV [\%], where EDV is the end-diastolic and ESV the end-systolic volume.

\section{Feature Tracking}

Feature tracking analysis was performed using dedicated software (Image-Arena ${ }^{\circledR}$, Version 4.6, TomTec Imaging Systems GmbH, Unterschleissheim, GERMANY). Both epi- and endocardial LV contours were drawn in order to achieve best tracking results. Furthermore, we explored the software's ability to track endoatrial contours in the LA. All contours were tracked semi-automatically in all views. The first slice was used to draw a contour that was then automatically propagated by the software to all slices of the cardiac cycle. Manual correction was performed where the automated tracking visually seemed to be inaccurate. Tracking data were only saved when the contours seemed to be accurate.

The following parameters were obtained: endocardial velocity (reflecting the speed of the endocardium; measured in $\mathrm{cm}^{*} \mathrm{~s}^{-1}$ for radial and longitudinal velocities or $\mathrm{deg}^{*} \mathrm{~s}^{-1}$ for circumferential velocities), strain (reflecting thickening/thinning in short-axis plane and shortening/lengthening in long-axis plane; indicated in percentage), endocardial strain rate (reflecting speed at which deformation occurs; measured in deformation* ${ }^{-1}$ ) and torsion (reflecting torsion between the base and the apex of the LV; calculated by dividing the difference of the absolute values of the circumferential velocities of the basal and the apical slice by their distance $(4 \mathrm{~cm})$, indicated in $\left.\operatorname{deg} * \mathrm{~s}^{-1} * \mathrm{~cm}^{-1}\right)$.

The 2- and 4-chamber views were used to determine all longitudinal parameters. Radial parameters were derived from both short-axis (LV only) and long-axis views (LV and LA). In the short-axis views, three slices were analysed: The nearest slice to the base in which a complete circle of myocardium was trackable throughout the cardiac cycle was selected as the 
basal slice. The mid-ventricular and apical slice was then chosen with sequential $2 \mathrm{~cm}$ gaps towards the apex [17].

Post-analysis processing included averaging of the values of the software-created 48 tracking points for each slice. Consequently, a curve of mean tracking values over the cardiac cycle was generated. Based on the corresponding time frame of the smallest ventricular area in the mid-ventricular short-axis slice, end-systolic time was determined for all views. To distinguish systolic from diastolic left heart function, the following values were calculated for velocities and strain rates: peak value during systole, time to systolic peak, time to systolic peak-systolic time-ratio, reverse peak value during diastole, diastolic time to reverse peak and diastolic time to diastolic peak-diastolic time-ratio. For strain and torsion values (unimodal shapes) time to peak was divided by the cardiac cycle length.

\section{Statistics}

All continuous variables were tested for normal distribution using the Kolmogorov-Smirnov tests. Normally distributed variables are presented as mean \pm standard deviation (SD). Nonparametric data are presented as median plus inter-quartile range, categorical variables are presented as frequencies and percentages.

Feature tracking values of AF patients after ablation were compared to the pretherapeutic values using the student's t-test for dependent samples in order to assess the effect of AF ablation on feature tracking parameters. A change in parameter was considered as improvement if either the peak value increased, the reverse peak increased in absolute value, the time to peak decreased, or the peak occurred earlier in the cardiac cycle. In analogue, a change in parameter was considered as worsening if either the peak value decreased, the reverse peak decreased in absolute value, the time to peak increased, or the peak occurred later in the cardiac cycle. 
We performed a random effects meta-analysis to determine the mean and $95 \%$ confidence for healthy controls from published literature using TomTec's feature tracking software. We then compared baseline strain data derived from our patients at baseline with the effect size for healthy controls derived by meta-analysis using tests for heterogeneity and we report the Q value and corresponding $\mathrm{p}$ value.

To assess intra-observer variability, F.C. analysed ten randomly selected pairs of datasets (each containing a baseline and follow-up CMR) twice with 2 months in between analyses. Intra-observer variability data are presented using the Bland and Altman approach determining the mean difference (mean bias) and the limits of agreement $( \pm 1.96 \mathrm{SD}$ and the coefficient of variability [SD of mean difference divided by sample mean] is reported).

A $p$ value of less than 0.05 was considered statistically significant. The number and direction of statistically significant effects were used to draw conclusions about presence of true effects. All statistical analyses were performed using dedicated software $\left(\mathrm{SAS}^{\circledR}\right.$ Version 9.3; SAS Institute Inc., Cary, NC, US and Comprehensive Meta Analysis ${ }^{\circledR}$ Version 2.2; Biostat, Englewood, NJ, US). 


\section{Results}

\section{Patient population}

Patients' were recruited between November 2010 and January 2012.

28 patients underwent CMR imaging both before (mean: $3 \pm 3$ days) and three months (3.4 \pm 1.1 months) after ablation procedure (56 scans in total). 17 patients were treated with WACA and 11 with Cryo. Median duration of AF before ablation was 51 months (IQR 2484). AF in all patients was refractory to at least one anti-arrhythmic drug (IQR 1-3, previous use of amiodarone in 8 patients). 12 Patients had hypertension (40\%), 3 had previous stroke (10\%) and 3 had a history of ischemic heart disease (10\%). None of the patients were diabetic or had significant valvular disease (defined as $\geq$ moderate regurgitant or stenotic valvular lesion). 17 patients (61\%) were free from $\mathrm{AF}$ at three months after a single procedure, and this was sustained at six months follow-up. 9 successes occurred in the cryoablated group (82\%), 8 in the WACA group (47\%). All recurrent arrhythmia was paroxysmal, and hence all patients were in sinus rhythm at baseline and three months scans.

Patient demographics are shown in table 1.

\section{Results from intra-observer variability analysis}

Figure 1 shows Bland-Altman plots for the intra-observer variability analysis. It shows a good agreement between the two repeated measurements with coefficients of variation ranging from $1.7 \%$ (end diastolic volume) to $25.6 \%$ (longitudinal strain). 


\section{Cardiac volumes and function}

LV EF was within the normal range and remained stable $(57 \pm 7 \%$ at baseline vs $55 \pm 7 \%$ at

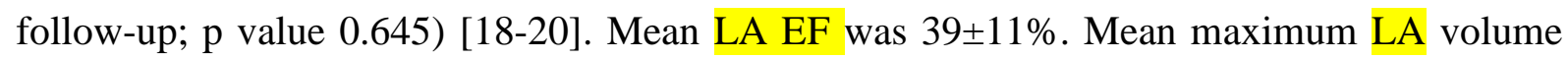
was $116 \pm 34 \mathrm{~mL} .4$ subjects had a reduced LV EF of $<50 \%(14 \%)$.

\section{Feature tracking data}

Feature tracking analysis both for LV and LA was feasible in all patients (see figure 2). Mean heart rate did not change significantly between baseline and follow-up $(63 \pm 13$ vs. $67 \pm 15$ bpm; $\mathrm{p}$ value 0.298$)$.

Among all 195 velocity, strain, strain rate and torsion parameters assessed by feature tracking, 27 showed a change (14\%). The following 9 improved significantly (5\% of parameters assessed): time to peak of LA radial velocity, both time to reverse peak and its ratio to diastolic length of LV longitudinal velocity, time to peak of LV apical strain rate, the reverse peaks of LV and LA longitudinal and radial strain rates and both time to peak and its ratio to the cardiac cycle length of left ventricular torsion. The following 12 parameters $(6 \%)$ worsened significantly: peak radial velocities of both all LV short axis slices (see figure 3) and LA long axis view, peak strain of LV mid-ventricular and apical circumferential strain, time to peak ratio of $\mathrm{LV}$ long axis and basal short axis strain, time to peak of left atrial longitudinal strain and reverse peaks of all three LV circumferential strain rates. Furthermore, 6 parameters worsened, but not significantly (3\%).

With regard to systolic and diastolic parameters, we could observe changes in 18 of 120 systolic parameters (15\%): 14 worsened (12\%) and 4 improved (3\%). In 9 of 75 diastolic parameters, values showed changes (12\%): 5 improvements (7\%) and 4 worsening (5\%).

Repeat analyses, excluding the 6 patients with impaired LV EF $(<50 \%)$ or those patients with unsuccessful ablation showed no significant differences in our findings. 
All changes in feature tracking values are summarized in table 2.

\section{Meta-analysis}

The results from the meta-analysis revealed that mean circumferential and longitudinal strain values of our patient collective at baseline didn't show significant differences to the values derived from healthy subjects in previously published studies $[21,22,4,23,7,6]$ (see figure 4). This lack of significant difference was reflected in Q values for circumferential strain of 0.01 ( $p$ value 0.921 ) and for longitudinal strain of 1.499 ( $p$ value 0.221 ).

\section{Discussion}

The main finding of our study is firstly that in this cohort of patients with AF there were no subtle abnormalities of systolic or diastolic function as a plausible underlying aetiology compared to normal controls in the literature. Secondly, elimination of paroxysmal AF by catheter ablation did not have a clear benefit in terms of LV function, albeit in a cohort with mostly normal LV function at baseline. The intra-observer variability suggest that semiautomated analysis using feature tracking software is feasible and robust and does not explain a lack of change due to large variability of outcome measures. In fact, our power calculation suggests, this is unlikely to be due to too small a sample size. The use of semi-automated feature tracking software for detailed analysis of systolic and diastolic function has now been validated in several studies. This paves the way for clinical studies examining its utility in a number of potential areas, such as quantifying mechanical dyssynchrony and patient selection for cardiac resynchronization therapy, assessment of ischaemia and viability, early detection 
of cardiomyopathies such as hypertrophic cardiomyopathy or arrhythmogenic cardiomyopathy and possibly detection of genotype positive but apparently phenotype negative patients.

The application of this technology to AF is particularly exciting because its aetiology is likely multifactorial and may well involve abnormalities of cardiac function and haemodynamics in a proportion of patients which causes atrial remodelling and thereby promotes $\mathrm{AF}[24,25]$. The onset of AF may also precipitate heart failure in some patients and increases mortality in those with pre-existing heart failure [26,27]. A greater understanding of what abnormalities promote $\mathrm{AF}$, how $\mathrm{AF}$ adversely affects the heart, and who will respond best to restoration of sinus rhythm will better equip us to prevent $\mathrm{AF}$ with upstream therapies and help select patients for curative strategies.

To our knowledge, this is the first study analysing deformation properties of both chambers of the left heart separately for systole and diastole by CMR feature tracking techniques in patients with AF. By studying patients pre- and post ablation we were able to study the effect of restoring sinus rhythm.

To assess whether feature tracking software allows a reliable analysis in patients with a history of AF, we performed an intra-observer variability analysis. Numerous publications focussing on feature tracking observer variability and inter-study reproducibility have shown that global circumferential and longitudinal strain parameters tended to be the most reproducible. Whilst Augustine et al. indicate coefficients of variation of $2.8 \%$ for circumferential and $12.3 \%$ for longitudinal measurements, Schuster et al. report $13.3 \%$ and $17.3 \%$, respectively [7,23]. Our results are in line with these numbers and support the notion that circumferential strain is the most reproducible measure of strain. Longitudinal strain showed a relatively high variation in our analysis. An explanation for this is that the 4chamber view is possibly affected by the breath-dependent position of the diaphragm as 
suggested by Schuster et al. [22]. Future studies should investigate whether these variations in rate or on differences in imaging resolution.

Results from our analysis of LV and LA function reveal that only minor changes in velocities, strains and strain rates were measurable with the feature tracking technique three months after ablation procedures. Since feature tracking is a relatively new tool in image analysis, this study is the first to investigate its clinical applicability in a cohort of patients with paroxysmal AF. Previous studies investigated cardiac wall motion in AF patients undergoing ablation using echocardiography speckle tracking analysis. Although the imaging modalities that underlie the two tracking techniques differ, they both aim to measure the same motion parameters. Whilst a number of studies could detect changes in both atrial and ventricular wall motion after ablation with the use of the speckle tracking technique [28-31], we could not observe similar changes of strains or velocities. One possible explanation for this might be that follow-up imaging at only three months after ablation procedures was too early to show delayed improvements in motion values. Tops et al. found significant changes in atrial strain and strain rate at $13 \pm 7$ months follow-up after radiofrequency ablation [31], whereas Reant et al. assessed LV strain more frequently at 1 and at 6 and 12 months [30]. They showed that LV function improved progressively during the first year and differed significantly from baseline only at the end of follow-up.

Another possible explanation could be found in the differing imaging modalities that underlie the two tracking techniques mentioned: Whilst echocardiography has the advantage of superior temporal resolution, CMR is superior in spatial resolution. In terms of endocardial border tracking during the cardiac cycle both excellent temporal and spatial resolution are desirable. The attempt to increase temporal resolution with maintained spatial resolution in CMR results in prolonged breath-hold time for the patient. However, clinical applicability of 
extended scan times remains a limitation. Further development of real-time cardiovascular magnetic resonance imaging could provide a solution to the limited frame rate in current CMR techniques compared to echocardiography as previously suggested by Nagel et al. [32]. In order to explore our patients' health status with regard to cardiac wall motion, we analyzed peak strain values of 266 healthy subjects from six studies. Results from this meta-analysis suggest that mean strain values of our patient cohort at baseline are very similar to the nonAF populations' values. Consequently, we assume that our AF patients did not have altered cardiac deformation before the ablation procedure. This would suggest that a possible postablation improvement in cardiac deformation parameters might therefore not have been feasible. Certain characteristics of our cohort may support this assumption: Whilst Reant et al. examined patients with an average duration of atrial fibrillation of 9 years, our patients underwent ablation procedures significantly earlier [30]. Furthermore, our cohort consisted only of patients with paroxysmal AF (self-terminating, usually within 48 hours), whereas previous studies included patients with persistent AF (AF episode either lasts longer than 7 days or requires termination) at considerable rates $(24 \%-33 \%)[33,28,31]$. Schneider et al. reported lower strain values in subjects with persistent $\mathrm{AF}$ as compared to paroxysmal AF and consequently our analysis might be influenced by the exclusion of patients with persistent AF [34]. However, we only included patients with paroxysmal AF who were in sinus rhythm at the time of imaging in order to get best imaging quality. Finally, mean LA EF in our cohort was $39 \pm 11 \%$ already at baseline, whereas Jahnke et al. found similar values only after successful ablation procedure ( $32 \pm 17 \%$ at baseline, significant improvement to $41 \pm 13 \%$ three months after ablation) [35].

The data of the current study must be interpreted in the context of the study design. First, although a power calculation suggests a power of around $90 \%$, our cohort was limited in size and detection of changes might still have been missed. However, our study design was based 
on previously reported sample size calculations: Morton et al. suggested a sample size of 29 to detect a change in strain of 5\% with $90 \%$ power and $\alpha$ error of 0.05 [36]. Secondly, the follow-up imaging in our study may have been performed too early to find relevant changes in feature tracking parameters. Future studies should investigate the long-term changes in cardiac wall motion with the help of feature tracking analysis. Finally, our study design did not include a healthy control group. We tried to overcome this by performing a meta-analysis of 266 healthy subjects from 6 published studies. Well-matched control groups are needed in future studies to better understand possible differences in feature tracking values of $\mathrm{AF}$ patients and healthy subjects.

In conclusion, feature tracking analysis appears to be a useful and reliable tool to determine treatment effects. Paroxysmal AF patients with grossly preserved LV ejection fraction do not appear to have subtle abnormalities of cardiac wall motion as an underlying aetiology. In this population with normal cardiac function at baseline, there were no subtle improvements in cardiac systolic or diastolic function detected following successful ablation.

\section{Acknowledgements}

The authors declare that they have no competing interests. 
1. Arbelo E, Brugada J, Hindricks G, Maggioni A, Tavazzi L, Vardas P, Anselme F, Inama G, Jais P, Kalarus Z, Kautzner J, Lewalter T, Mairesse G, Perez-Villacastin J, Riahi S, Taborsky M, Theodorakis G, Trines S (2012) ESC-EURObservational Research Programme: the Atrial Fibrillation Ablation Pilot Study, conducted by the European Heart Rhythm Association. Europace : European pacing, arrhythmias, and cardiac electrophysiology : journal of the working groups on cardiac pacing, arrhythmias, and cardiac cellular electrophysiology of the European Society of Cardiology 14 (8):1094-1103. doi:10.1093/europace/eus153

2. Tops LF, Bax JJ, Zeppenfeld K, Jongbloed MR, van der Wall EE, Schalij MJ (2006) Effect of radiofrequency catheter ablation for atrial fibrillation on left atrial cavity size. Am J Cardiol 97 (8):1220-1222. doi:10.1016/j.amjcard.2005.11.043

3. Reant P, Lafitte S, Jais P, Serri K, Weerasooriya R, Hocini M, Pillois X, Clementy J, Haissaguerre M, Roudaut R (2005) Reverse remodeling of the left cardiac chambers after catheter ablation after 1 year in a series of patients with isolated atrial fibrillation. Circulation 112 (19):2896-2903. doi:10.1161/CIRCULATIONAHA.104.523928

4. Morton G, Schuster A, Jogiya R, Kutty S, Beerbaum P, Nagel E (2012) Inter-study reproducibility of cardiovascular magnetic resonance myocardial feature tracking. Journal of cardiovascular magnetic resonance : official journal of the Society for Cardiovascular Magnetic Resonance 14:43. doi:10.1186/1532-429X-14-43 5. Morton G, Jogiya R, Plein S, Schuster A, Chiribiri A, Nagel E (2012) Quantitative cardiovascular magnetic resonance perfusion imaging: inter-study reproducibility. Eur Heart J Cardiovasc Imaging 13 (11):954-960. doi:10.1093/ehjci/jes103

6. Kempny A, Fernandez-Jimenez R, Orwat S, Schuler P, Bunck AC, Maintz D, Baumgartner H, Diller GP (2012) Quantification of biventricular myocardial function using cardiac magnetic resonance feature tracking, endocardial border delineation and echocardiographic speckle tracking in patients with repaired tetralogy of Fallot and healthy controls. Journal of cardiovascular magnetic resonance : official journal of the Society for Cardiovascular Magnetic Resonance 14:32. doi:10.1186/1532-429X-14-32

7. Augustine D, Lewandowski AJ, Lazdam M, Rai A, Francis J, Myerson S, Noble A, Becher H, Neubauer S, Petersen SE, Leeson P (2013) Global and regional left ventricular myocardial deformation measures by magnetic resonance feature tracking in healthy volunteers: comparison with tagging and relevance of gender. Journal of cardiovascular magnetic resonance : official journal of the Society for Cardiovascular Magnetic Resonance 15 (1):8. doi:10.1186/1532-429X-15-8 
8. Hsu LF, Jais P, Sanders P, Garrigue S, Hocini M, Sacher F, Takahashi Y, Rotter M, Pasquie JL, Scavee C,

Bordachar P, Clementy J, Haissaguerre M (2004) Catheter ablation for atrial fibrillation in congestive heart failure. N Engl J Med 351 (23):2373-2383. doi:10.1056/NEJMoa041018

9. Gentlesk PJ, Sauer WH, Gerstenfeld EP, Lin D, Dixit S, Zado E, Callans D, Marchlinski FE (2007) Reversal of left ventricular dysfunction following ablation of atrial fibrillation. J Cardiovasc Electrophysiol 18 (1):9-14. doi:10.1111/j.1540-8167.2006.00653.x

10. Chen MS, Marrouche NF, Khaykin Y, Gillinov AM, Wazni O, Martin DO, Rossillo A, Verma A, Cummings J, Erciyes D, Saad E, Bhargava M, Bash D, Schweikert R, Burkhardt D, Williams-Andrews M, Perez-Lugones A, Abdul-Karim A, Saliba W, Natale A (2004) Pulmonary vein isolation for the treatment of atrial fibrillation in patients with impaired systolic function. J Am Coll Cardiol 43 (6):1004-1009. doi:10.1016/j.jacc.2003.09.056

11. Hunter RJ, Jones DA, Boubertakh R, Malcolme-Lawes LC, Kanagaratnam P, Juli CF, Davies DW, Peters NS, Baker V, Earley MJ, Sporton S, Davies LC, Westwood M, Petersen SE, Schilling RJ (2012) Diagnostic Accuracy of Cardiac Magnetic Resonance Imaging in the Detection and Characterization of Left Atrial Catheter Ablation Lesions: A Multicenter Experience. Journal of cardiovascular electrophysiology. doi:10.1111/jce.12063 12. Hunter RJ, Berriman TJ, Diab I, Baker V, Finlay M, Richmond L, Duncan E, Kamdar R, Thomas G, Abrams D, Dhinoja M, Sporton S, Earley MJ, Schilling RJ (2010) Long-term efficacy of catheter ablation for atrial fibrillation: impact of additional targeting of fractionated electrograms. Heart 96 (17):1372-1378. doi:10.1136/hrt.2009.188128

13. Calkins H, Kuck KH, Cappato R, Brugada J, Camm AJ, Chen SA, Crijns HJ, Damiano RJ, Jr., Davies DW, DiMarco J, Edgerton J, Ellenbogen K, Ezekowitz MD, Haines DE, Haissaguerre M, Hindricks G, Iesaka Y, Jackman W, Jalife J, Jais P, Kalman J, Keane D, Kim YH, Kirchhof P, Klein G, Kottkamp H, Kumagai K, Lindsay BD, Mansour M, Marchlinski FE, McCarthy PM, Mont JL, Morady F, Nademanee K, Nakagawa H, Natale A, Nattel S, Packer DL, Pappone C, Prystowsky E, Raviele A, Reddy V, Ruskin JN, Shemin RJ, Tsao HM, Wilber D (2012) 2012 HRS/EHRA/ECAS Expert Consensus Statement on Catheter and Surgical Ablation of Atrial Fibrillation: recommendations for patient selection, procedural techniques, patient management and follow-up, definitions, endpoints, and research trial design. Europace 14 (4):528-606. doi:10.1093/europace/eus027

14. Papavassiliu T, Kuhl HP, Schroder M, Suselbeck T, Bondarenko O, Bohm CK, Beek A, Hofman MM, van Rossum AC (2005) Effect of endocardial trabeculae on left ventricular measurements and measurement reproducibility at cardiovascular MR imaging. Radiology 236 (1):57-64. doi:10.1148/radiol.2353040601 
15. Childs H, Ma L, Ma M, Clarke J, Cocker M, Green J, Strohm O, Friedrich MG (2011) Comparison of long and short axis quantification of left ventricular volume parameters by cardiovascular magnetic resonance, with ex-vivo validation. J Cardiovasc Magn Reson 13:40. doi:10.1186/1532-429X-13-40

16. Hof IE, Velthuis BK, Van Driel VJ, Wittkampf FH, Hauer RN, Loh P (2010) Left atrial volume and function assessment by magnetic resonance imaging. J Cardiovasc Electrophysiol 21 (11):1247-1250. doi:10.1111/j.1540-8167.2010.01805.x

17. Harrild DM, Han Y, Geva T, Zhou J, Marcus E, Powell AJ (2012) Comparison of cardiac MRI tissue tracking and myocardial tagging for assessment of regional ventricular strain. The international journal of cardiovascular imaging 28 (8):2009-2018. doi:10.1007/s10554-012-0035-3

18. Alfakih K, Plein S, Thiele H, Jones T, Ridgway JP, Sivananthan MU (2003) Normal human left and right ventricular dimensions for MRI as assessed by turbo gradient echo and steady-state free precession imaging sequences. Journal of magnetic resonance imaging : JMRI 17 (3):323-329. doi:10.1002/jmri.10262

19. Maceira AM, Prasad SK, Khan M, Pennell DJ (2006) Normalized left ventricular systolic and diastolic function by steady state free precession cardiovascular magnetic resonance. Journal of cardiovascular magnetic resonance : official journal of the Society for Cardiovascular Magnetic Resonance 8 (3):417-426

20. Hudsmith LE, Petersen SE, Francis JM, Robson MD, Neubauer S (2005) Normal human left and right ventricular and left atrial dimensions using steady state free precession magnetic resonance imaging. Journal of cardiovascular magnetic resonance : official journal of the Society for Cardiovascular Magnetic Resonance 7 $(5): 775-782$

21. Kadiyala MT, R.; Bertman, K.; Pollack, S.; Reichek, N. (2011) Feature Tracking: a novel method to analyze myocardial strain: Results from the CMR strain study in healthy volunteers. Paper presented at the SCMR/Euro CMR Joint Scientific Sessions, Nice, France, 2 February 2011

22. Schuster A, Kutty S, Padiyath A, Parish V, Gribben P, Danford DA, Makowski MR, Bigalke B, Beerbaum P, Nagel E (2011) Cardiovascular magnetic resonance myocardial feature tracking detects quantitative wall motion during dobutamine stress. Journal of cardiovascular magnetic resonance : official journal of the Society for Cardiovascular Magnetic Resonance 13:58. doi:10.1186/1532-429X-13-58

23. Schuster A, Morton G, Hussain ST, Jogiya R, Kutty S, Asrress KN, Makowski MR, Bigalke B, Perera D, Beerbaum P, Nagel E (2013) The intra-observer reproducibility of cardiovascular magnetic resonance myocardial feature tracking strain assessment is independent of field strength. European journal of radiology 82 (2):296-301. doi:10.1016/j.ejrad.2012.11.012 
24. Kannel WB, Abbott RD, Savage DD, McNamara PM (1982) Epidemiologic features of chronic atrial fibrillation: the Framingham study. The New England journal of medicine 306 (17):1018-1022. doi:10.1056/NEJM198204293061703

25. Hunter RJ, Liu Y, Lu Y, Wang W, Schilling RJ (2012) Left atrial wall stress distribution and its relationship to electrophysiologic remodeling in persistent atrial fibrillation. Circulation Arrhythmia and electrophysiology 5 (2):351-360. doi:10.1161/CIRCEP.111.965541

26. Mamas MA, Caldwell JC, Chacko S, Garratt CJ, Fath-Ordoubadi F, Neyses L (2009) A meta-analysis of the prognostic significance of atrial fibrillation in chronic heart failure. European journal of heart failure 11 (7):676683. doi:10.1093/eurjhf/hfp085

27. Wang TJ, Larson MG, Levy D, Vasan RS, Leip EP, Wolf PA, D'Agostino RB, Murabito JM, Kannel WB, Benjamin EJ (2003) Temporal relations of atrial fibrillation and congestive heart failure and their joint influence on mortality: the Framingham Heart Study. Circulation 107 (23):2920-2925. doi:10.1161/01.CIR.0000072767.89944.6E

28. Mirza M, Caracciolo G, Khan U, Mori N, Saha SK, Srivathsan K, Altemose G, Scott L, Sengupta P, Jahangir A (2011) Left atrial reservoir function predicts atrial fibrillation recurrence after catheter ablation: a twodimensional speckle strain study. J Interv Card Electrophysiol 31 (3):197-206. doi:10.1007/s10840-011-9560-6

29. Hammerstingl C, Schwekendiek M, Momcilovic D, Schueler R, Sinning JM, Schrickel JW, Mittmann-Braun E, Nickenig G, Lickfett L (2012) Left atrial deformation imaging with ultrasound based two-dimensional speckle-tracking predicts the rate of recurrence of paroxysmal and persistent atrial fibrillation after successful ablation procedures. J Cardiovasc Electrophysiol 23 (3):247-255. doi:10.1111/j.1540-8167.2011.02177.x

30. Reant P, Lafitte S, Bougteb H, Sacher F, Mignot A, Douard H, Blanc P, Hocini M, Clementy J, Haissaguerre M, Roudaut R, Jais P (2009) Effect of catheter ablation for isolated paroxysmal atrial fibrillation on longitudinal and circumferential left ventricular systolic function. Am J Cardiol 103 (2):232-237. doi:10.1016/j.amjcard.2008.08.070

31. Tops LF, Delgado V, Bertini M, Marsan NA, Den Uijl DW, Trines SA, Zeppenfeld K, Holman E, Schalij MJ, Bax JJ (2011) Left atrial strain predicts reverse remodeling after catheter ablation for atrial fibrillation. J Am Coll Cardiol 57 (3):324-331. doi:10.1016/j.jacc.2010.05.063

32. Nagel E, Schneider U, Schalla S, Ibrahim T, Schnackenburg B, Bornstedt A, Klein C, Lehmkuhl HB, Fleck E (2000) Magnetic resonance real-time imaging for the evaluation of left ventricular function. J Cardiovasc Magn Reson 2 (1):7-14 
33. Camm AJ, Kirchhof P, Lip GY, Schotten U, Savelieva I, Ernst S, Van Gelder IC, Al-Attar N, Hindricks G, Prendergast B, Heidbuchel H, Alfieri O, Angelini A, Atar D, Colonna P, De Caterina R, De Sutter J, Goette A, Gorenek B, Heldal M, Hohloser SH, Kolh P, Le Heuzey JY, Ponikowski P, Rutten FH (2010) Guidelines for the management of atrial fibrillation: the Task Force for the Management of Atrial Fibrillation of the European Society of Cardiology (ESC). Eur Heart J 31 (19):2369-2429. doi:10.1093/eurheartj/ehq278

34. Schneider C, Malisius R, Krause K, Lampe F, Bahlmann E, Boczor S, Antz M, Ernst S, Kuck KH (2008) Strain rate imaging for functional quantification of the left atrium: atrial deformation predicts the maintenance of sinus rhythm after catheter ablation of atrial fibrillation. Eur Heart J 29 (11):1397-1409. doi:10.1093/eurheartj/ehn168

35. Jahnke C, Fischer J, Gerds-Li JH, Gebker R, Manka R, Fleck E, Paetsch I, Kriatselis C (2011) Serial monitoring of reverse left-atrial remodeling after pulmonary vein isolation in patients with atrial fibrillation: a magnetic resonance imaging study. Int J Cardiol 153 (1):42-46. doi:10.1016/j.ijcard.2010.08.034

36. Morton G, Schuster A, Jogiya R, Kutty S, Beerbaum P, Nagel E (2012) Inter-study reproducibility of cardiovascular magnetic resonance myocardial feature tracking. J Cardiovasc Magn Reson 14:43. doi:10.1186/1532-429X-14-43 
Figure legends

Figure 1: Intra-observer variability for the assessment of left ventricular circumferential and longitudinal strain and volumes.

$E D V=e n d$-diastolic volume; $E S V=e n d$-systolic volume; $C O V=$ coefficient of variation

Figure 2: Feasibility of feature tracking velocity analysis in left ventricle and atrium

Feature tracking analysis shown for radial and longitudinal velocities of the left ventricle (above) and the left atrium (below). The 48 blue lines reflect tracking of the endocardial borders. The length of the green vectors (middle) reflects absolute values of velocities.

Figure 3: Radial velocity curve of endocardium (short axis mid-ventricular view). Figure showing baseline (red) and three-month follow-up (red) curve of radial velocity [ $\mathrm{cm}^{*} \mathrm{~s}$-1] in midventricular short axis view. Vertical arrows indicate peak velocities.

Figure 4: Comparison of baseline strain values with previously published strain values derived from feature tracking analysis.

$A F=$ atrial fibrillation $; C I=$ confidence interval 


\section{Effect of atrial fibrillation ablation on myocardial function: insights from cardiac magnetic resonance feature tracking analysis}

Felix Ceelen ${ }^{1,2}$, Ross J Hunter ${ }^{1}$, Redha Boubertakh ${ }^{1}$, Wieland H Sommer ${ }^{2}$, Marco Armbruster $^{2}$, Richard J Schilling ${ }^{1}$, Steffen E Petersen ${ }^{1 *}$

1 Advanced Cardiovascular Imaging, NIHR Cardiovascular Biomedical Research Unit at Barts, William Harvey Research Institute, Queen Mary University of London, UK

${ }^{2}$ Department of Clinical Radiology, University of Munich, Germany

Email: Felix.Ceelen@campus.lmu.de; Ross.Hunter@bartshealth.nhs.uk;

R.Boubertakh@qmul.ac.uk; Wieland.Sommer@med.uni-muenchen.de;

Marco.Armbruster@campus.lmu.de; R.Schilling@qmul.ac.uk; S.E.Petersen@qmul.ac.uk

*Corresponding Author

Steffen E Petersen, MD DPHIL (Oxon) FESC FACC

Reader in Advanced Cardiovascular Imaging

Centre lead for Advanced Cardiovascular Imaging

NIHR Cardiovascular Biomedical Research Unit at Barts

Barts and The London School of Medicine and Dentistry

Queen Mary, University of London

The London Chest Hospital, Bonner Road, London E2 9JX, UK

Email: S.E.Petersen@qmul.ac.uk 

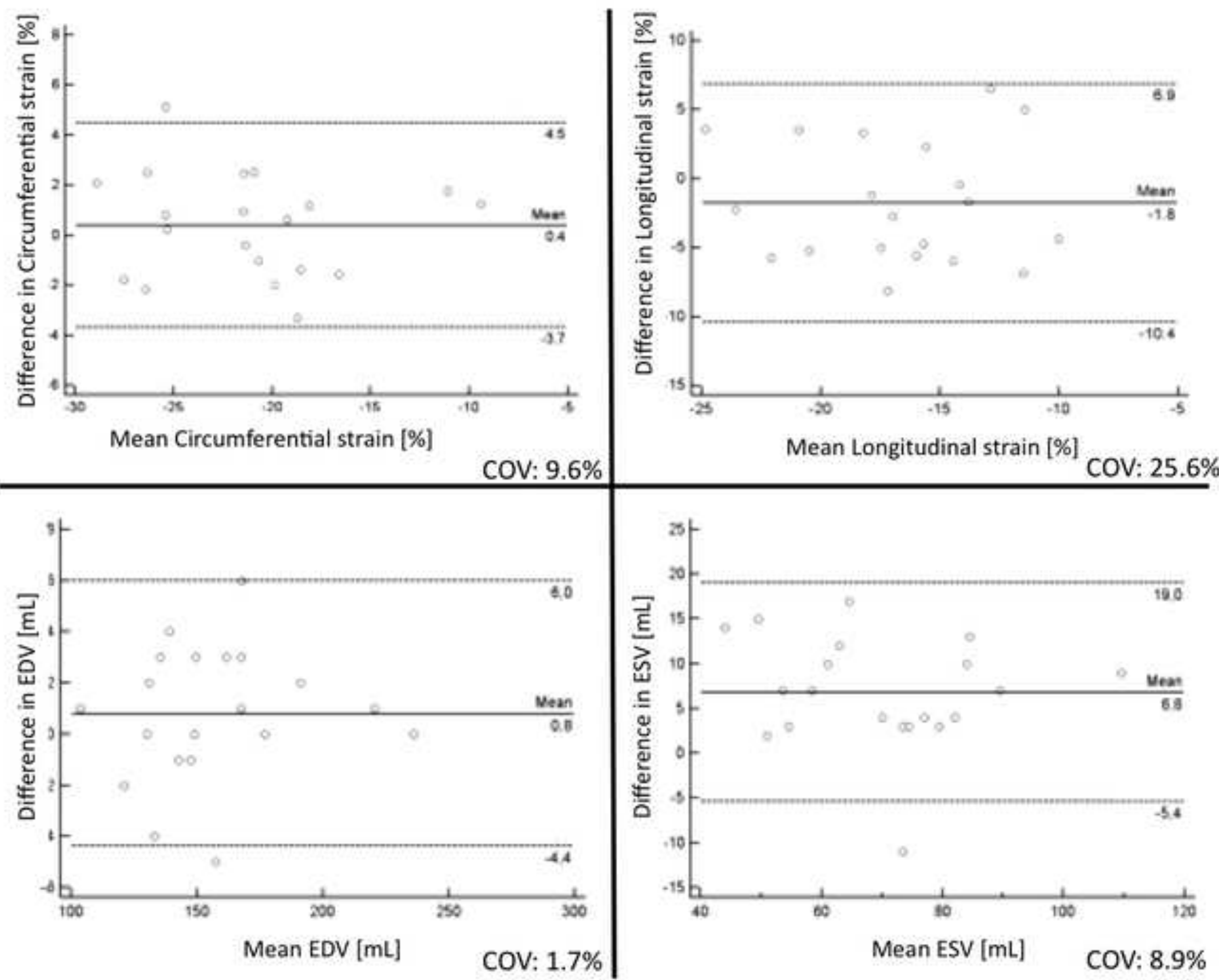


\section{Figure 2}

Click here to download high resolution image

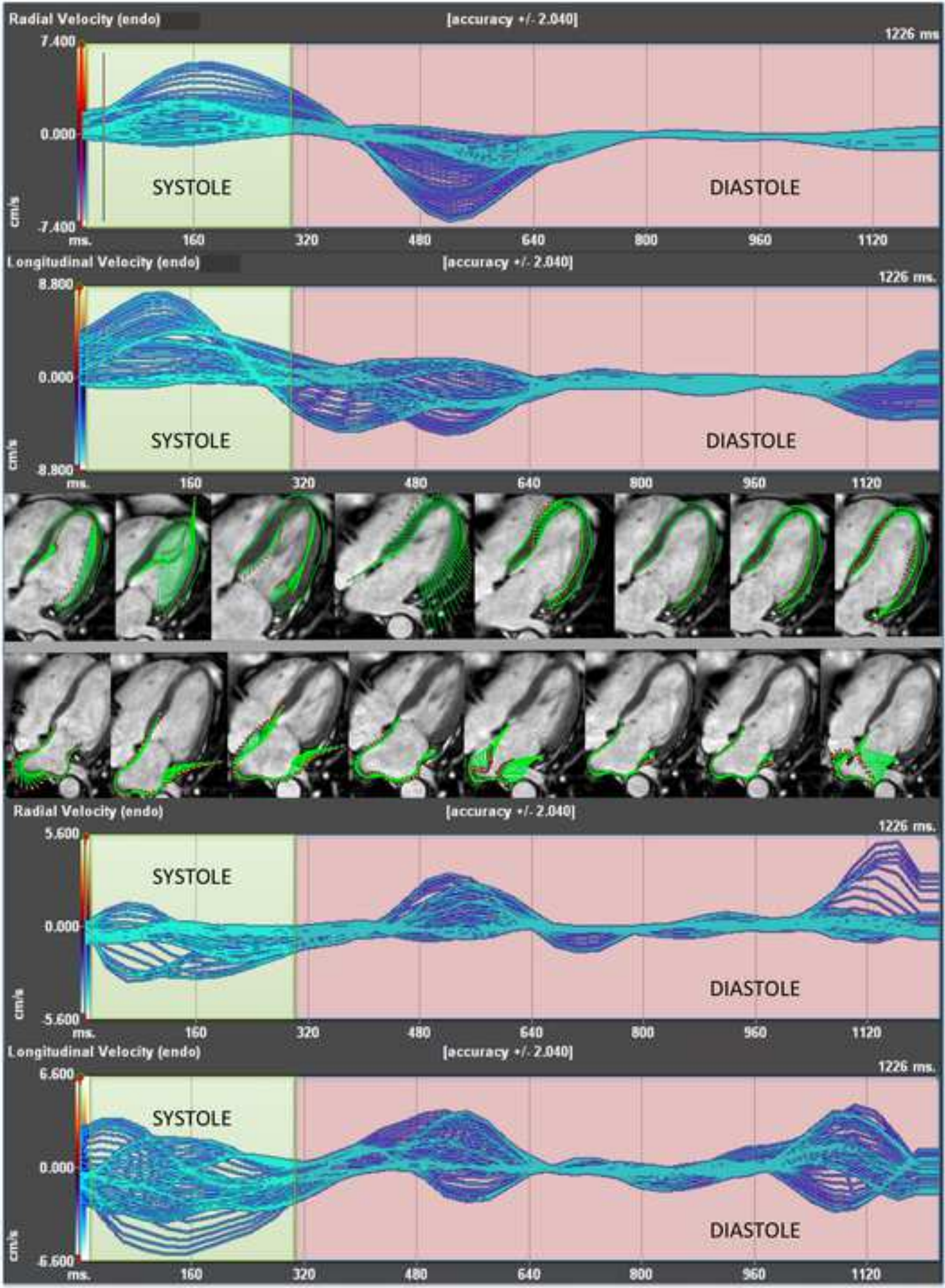


Click here to download high resolution image

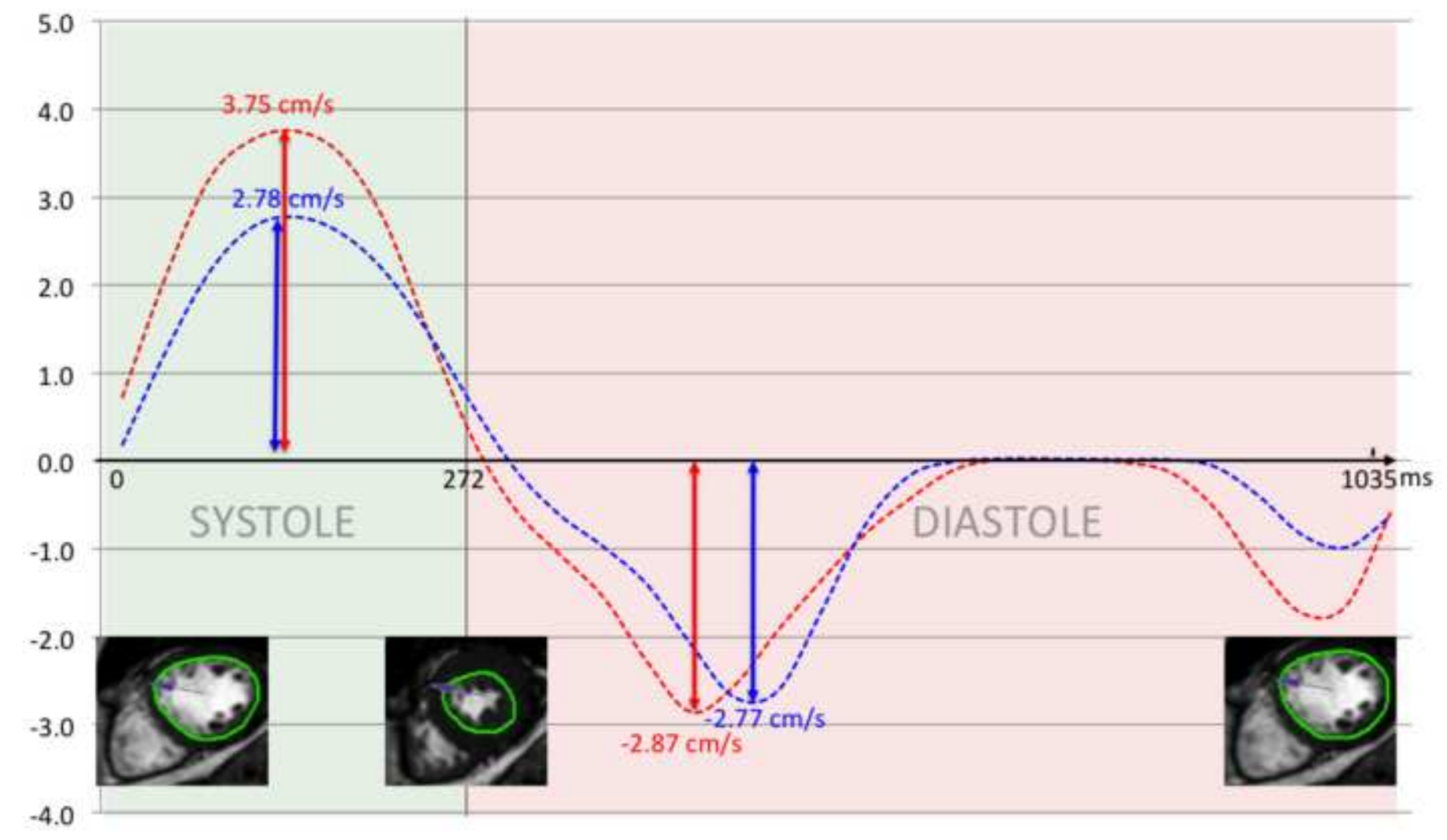

Click here 


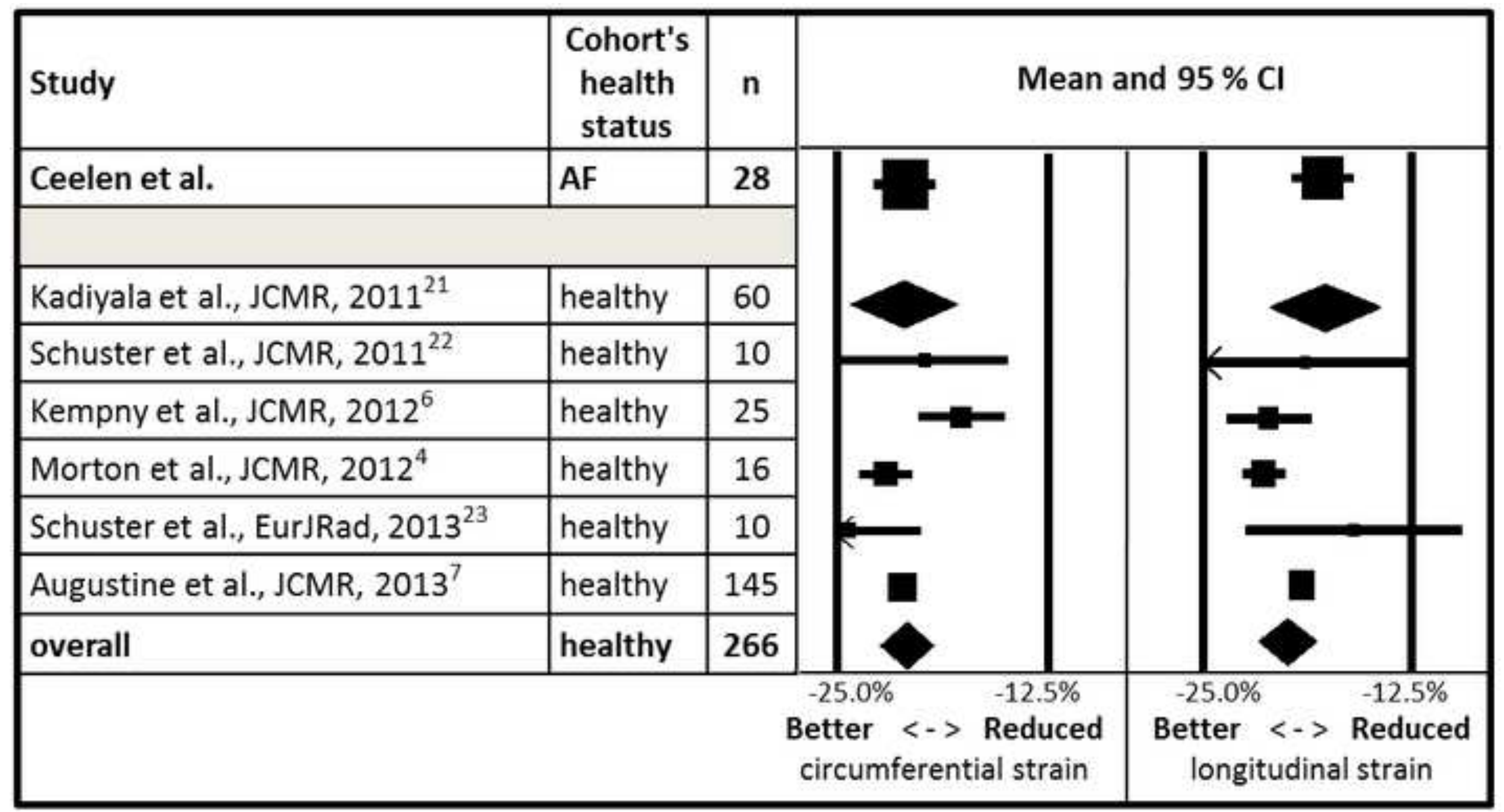




\section{Tables}

Table 1: Patients' baseline characteristics

\begin{tabular}{|c|c|c|}
\hline & & $\begin{array}{c}\text { Patients } \\
\mathrm{n}=28\end{array}$ \\
\hline Age & yrs & $61(51-69)$ \\
\hline Male gender & $\mathrm{n}$ & $20(71)$ \\
\hline Duration of AF & mo & $51(24-84)$ \\
\hline Anti-Arrhythmic drugs failed & $\mathrm{n}$ & $2(1-3)$ \\
\hline Hypertension & $\mathrm{n}$ & $12(40)$ \\
\hline Previous stroke & $\mathrm{n}$ & $3(10)$ \\
\hline Ischaemic heart disease & $\mathrm{n}$ & $3(10)$ \\
\hline Diabetes & $\mathrm{n}$ & $0(0)$ \\
\hline Time between baseline CMR and ablation & $\mathrm{d}$ & $3(3)$ \\
\hline Time between ablation and follow-up CMR & mo & $3.4(1.1)$ \\
\hline Left ventricular EF & $\%$ & $57(7)$ \\
\hline Left atrial EF & $\%$ & $39(11)$ \\
\hline Maximum left atrial volume & $\mathrm{mL}$ & $116(34)$ \\
\hline Wide area circumferential radiofrequency ablation & $\mathrm{n}$ & $17(61)$ \\
\hline Ablation success at 3 and 6 months follow-up & $\mathrm{n}$ & $17(61)$ \\
\hline Wide area circumferential ablation & $\mathrm{n}$ & $8(47)$ \\
\hline Cryoablation & $\mathrm{n}$ & $9(82)$ \\
\hline
\end{tabular}

yrs=years; mo=months; $d=$ days; $E F=$ ejection fraction; $C M R=$ cardiovascular magnetic resonance;

Nonparametric data are presented as median plus inter-quartile range, categorical variables are presented as frequencies and percentages. 
Table 2: Summary of changes of all feature tracking parameters

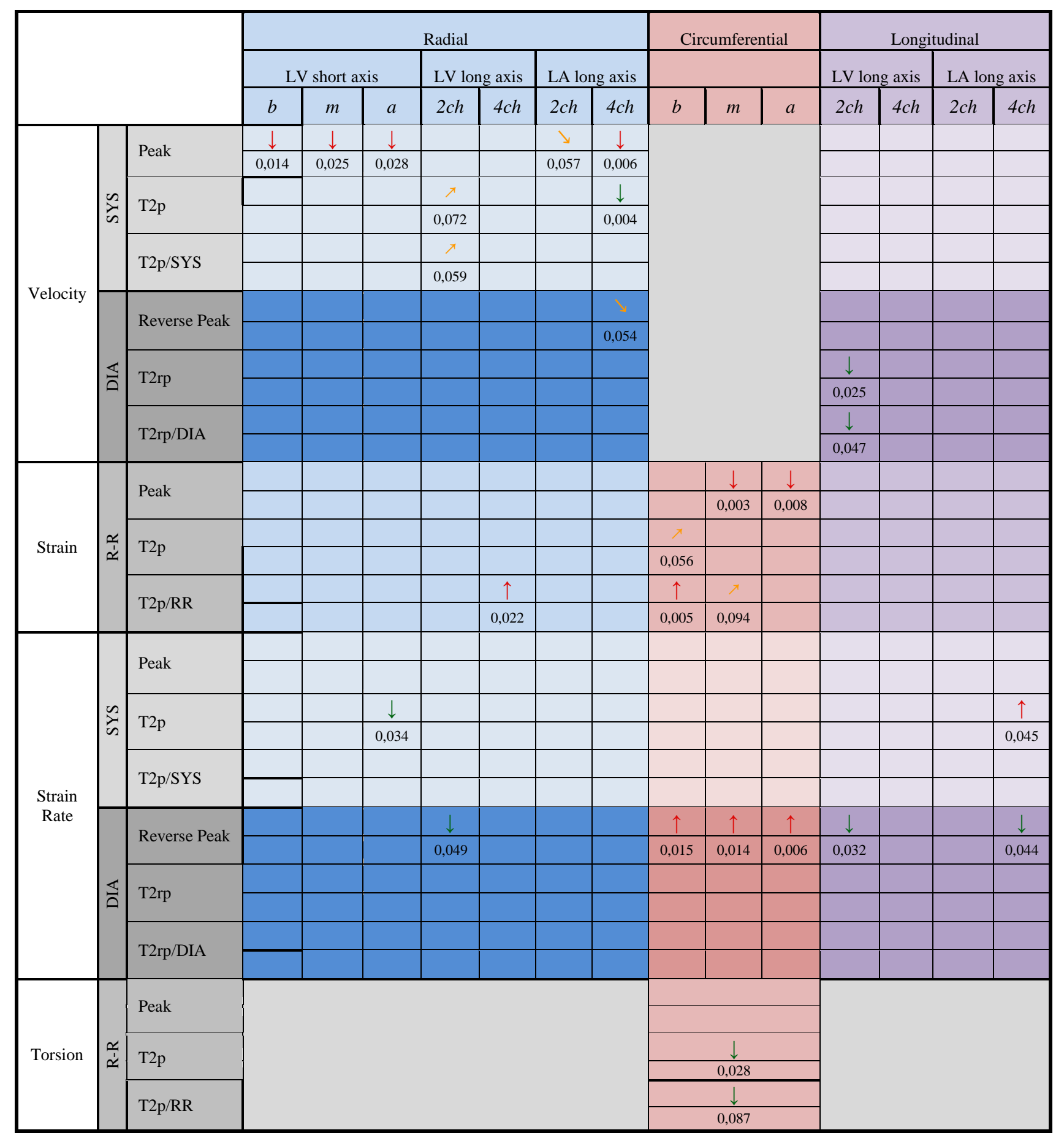

$R-R=$ cardiac cycle; $b=$ basal; $a=$ apical; $m=$ midventricular; $L V=l e f t$ ventricle; $L A=l e f t$ atrium; $2 c h=2$-chamber view; $4 c h=4$ chamber view; $T 2 p=$ time to peak; $T 2 r p=$ time to reverse peak

Red arrows indicate significant worsening of values and the direction (decreased or increased absolute values), green arrows indicate significant improvement of values and direction (increased or decreased absolute values) ( $p$ value $<0.05$ ). Values that nearly reached significance ( $p$ value $>0.05$ but $<0.10)$ are indicated as orange arrows and reflect worsening. $P$ Values are indicated below the arrows. 


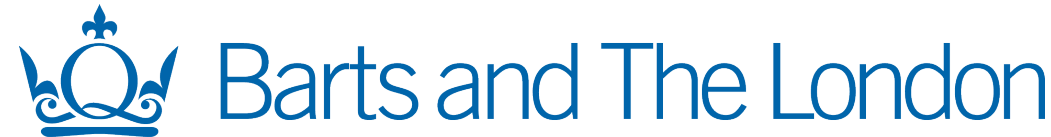

School of Medicine and Dentistry

WILLIAM HARVEY RESEARCH INSTITUTE

Steffen E Petersen

Professor of Cardiovascular Medicine Centre Lead

Centre for Advanced Cardiovascular Imaging William Harvey Research Institute

Barts and The London

NIHR Biomedical Research Unit

The London Chest Hospital

Bonner Road

London E2 9JX, UK

s.e.petersen@qmul.ac.uk

August 22, 2013

\section{RE: Re-submission CAIM-D-13-00266}

Dear Professor Reiber, dear Dr Stillman,

Thank you very much for your email regarding our submission ID CAIM-D-13-00266 entitled "Effect of atrial fibrillation ablation on myocardial function: insights from cardiac magnetic resonance feature tracking analysis". We are very pleased that the reviewers have recommended publication.

We appreciate a lot the comments regarding the manuscript, which we have addressed in a separate rebuttal section below. We valued the reviewers' comments and suggestions and hope that this revised and improved manuscript is acceptable for publication in The International Journal of Cardiovascular Imaging.

Yours sincerely,

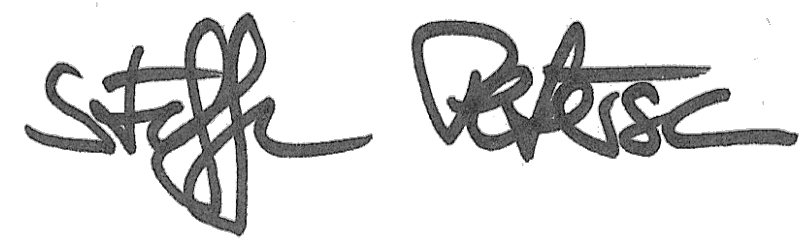

Steffen Petersen, MD DPHIL FRCP FESC FACC 


\section{The International Journal of \\ CARDIOVASCULAR IMAGING Authorship and Disclosure Form}

$\overline{\text { MANUSCRIPT ID NUMBER }}$

Effect of atrial fibrillation ablation

\section{Article title (first few words)}

First Author: Felix Ceelen

E-mail: Felix. Ceelen@campus. Imu. de

After submission of this agreement signed by all authors, changes of authorship or in the order of the authors listed will not be accepted by Springer.

\section{AUTHORSHIP}

I, the undersigned author(s), certify that:

- I have seen and approved the final version of the manuscript, and all subsequent versions.

- I have made substantial contributions to conception and design, or acquisition of data, or analysis and interpretation of data;

- I have drafted the article or revised it critically for important intellectual content.

I accept public responsibility for it, and believe it represents valid work. As an author of this article, I also certify that none of the material in the manuscript has been previously published, nor is it included in any other manuscript. I certify that this manuscript is not under consideration for publication elsewhere, nor has it been submitted or accepted in another publication in any form. The rights or interest in the manuscript have not been assigned to any third party.

Moreover, should the editor of The International Journal of Cardiovascular Imaging request the data upon which the manuscript is based, I shall produce it. I also certify that I have read and complied with the copyright information, as found on the journal's home page website.

\section{FINANCIAL DISCLOSURE/CONFLICT OF INTEREST}

I certify that any financial interests such as employment, stock ownership, honoraria, paid expert testimony, as well as any personal relationships, academic competition, and intellectual passion which may inappropriately influence my actions, have been disclosed on a separate attachment.

All funding sources supporting the work and all institutional or corporate affiliations of mine are acknowledged in a footnote.

I have had full access to all the data in the study (if applicable) and thereby accept full responsibility for the integrity of the data and the accuracy of the data analysis.

By checking the box next to my signature I assert that there are no conflicts of interest (both personal and institutional) regarding specific financial interests that are relevant to the work conducted or reported in this manuscript. 


\section{The International Journal of CARDIOVASCULAR IMAGING Authorship and Disclosure Form}

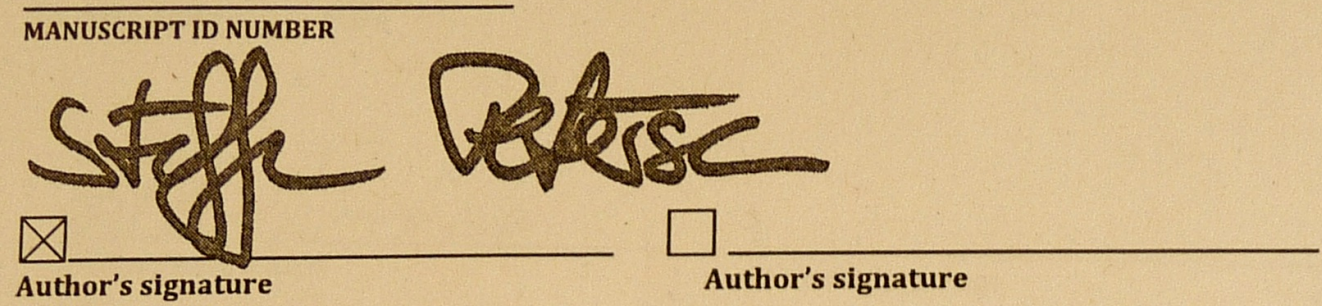

Steffen E Petersen, 06/22/13

Printed name and date

Printed name and date

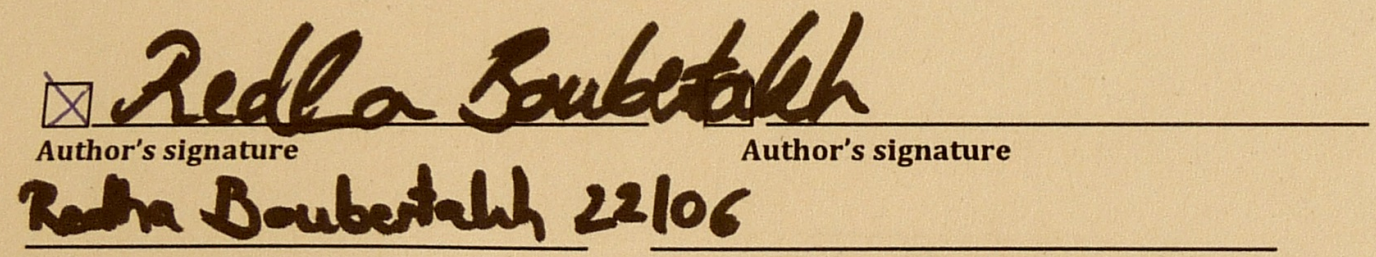

Printed name and date

Printed name and date

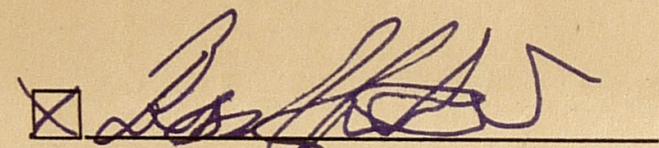

Author's signature

Author's signature
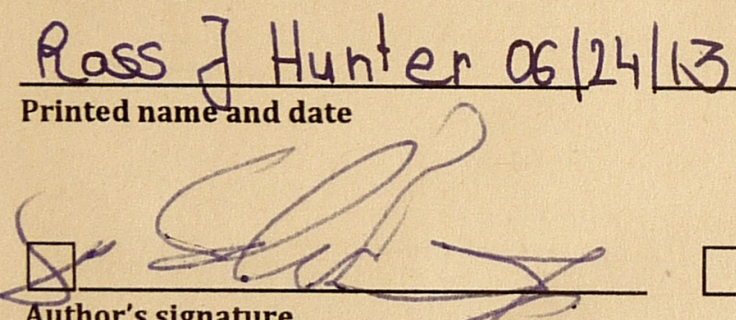

Author's signature Author's signature

Printed name and date

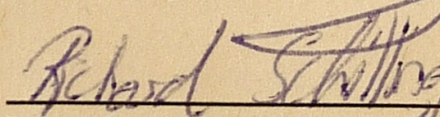

Printed name and date

Printed name and date

Completed forms can be scanned and included as a pdf file during the online submission process as a supplemental file not for review. Please contact the appropriate editorial office should you experience problems with scanning the document. 


\section{The International Journal of CARDIOVASCULAR IMAGING Authorship and Disclosure Form}

MANUSCRIPT ID NUMBER

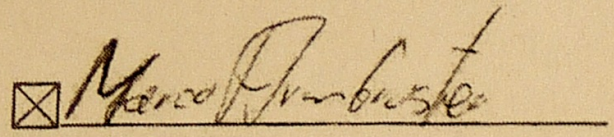

Author's signature

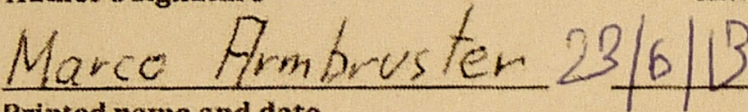

Printed name and date

Printed name and date

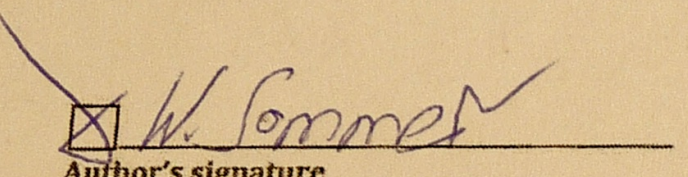

Author's signature

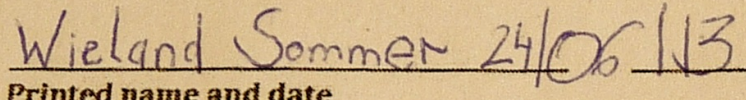

Printed name and date

Printed name and date

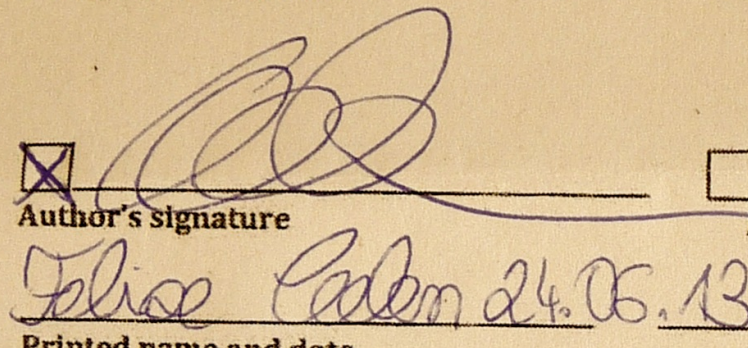

Author's signature

Printed name and date

Printed name and date

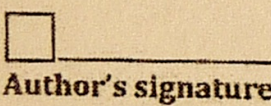

Author's signature

Printed name and date

Printed name and date

Completed forms can be scanned and included as a pdf file during the online submission process as a supplemental file not for review. Please contact the appropriate editorial office should you experience problems with scanning the document. 